\title{
EFFECTS OF NONINVASIVE PLETH VARIABILITY INDEX MONITORING ON INTRAOPERATIVE HEMODYNAMICS IN TOTAL HIP SURGERIES
}

\author{
Sen G., Duger C., Kaygusuz K., Ozdemir Kol I., Isbir A.C., Gursoy S, \\ Cumhuriyet University, Dept of Anaesthesiology \& Intensive Care, \\ Sivas, Turkey
}

Background and Goal of Study: In this study, we aimed to compare the effects of standard and PVI monitoring techniques on hemodynamic parameters in the patients who undergo total hip arthroplasty which is performed under general anesthesia and are followed with standard invasive monitoring and with noninvasive PVI, afterwards.

Materials and Methods: In the study, after approval by the local Ethics Committee taken, the effectiveness of PVI measurements and standard monitoring measurements on hemodynamic parameters of a total number of 82 patients, ASA I-II, 30-85 years old, who did undergo total hip arthroplasty under general anesthesia were studied prospectively. In this study, PVI monitoring group compared with the standard set of monitoring group. Patients' SBP, DBP and MBP values measured at different times were compared and there was significant difference between groups. Measurements of standard monitoring were compared to basal measurements at 30th, 60th, 90th minutes,

Results and Discussion: During the study, when PVI measurements taken at different times were compared, there were no significant differences between the values. Despite this, PVI measurements showed a decrease in time.
The initial and final $\mathrm{Hgb}$ values of the patients in both groups included in the study were compared and no significant differences were found. The initial $\mathrm{Hgb}$ values of the patients in both groups were compared and significant differences were found; however, there were no significant differences between final $\mathrm{Hgb}$ values. The patients in both groups were compared in terms of the total fluid, blood and blood products. There were no significant differences between the groups in terms of blood and blood products but when total fluids given to the patients were compared significant differences found between the groups. Less fluid replacement was given to the PVI monitoring group.

Conclusion(s): Using noninvasive PVI monitoring in following up the hemodynamic parameters and providing the hemodynamic stability of the patients who are under general anesthesia is more practical, easier to use and causing no complications in comparison to standard monitoring. Nevertheless, further investigation on PVI monitoring are needed to illuminate the effectiveness of PVI monitoring on other parameters except for fluid management. 